\title{
La ortografía desde los relatos anecdóticos del abuelo
}

\section{The orthography from grandfather anecdotal stories}

Fecha de recepción: 1 de Marzo de 2016.

Fecha de aprobación: 19 de Octubre de 2016.

Artículo de Reflexión

\section{Resumen}

A través de la experiencia de los autores, es posible inferir que las anécdotas del abuelo, específicamente la intitulada: "el Diánchiro de Carboneras", brinda algunas estrategias en la enseñanza ortográfica de las palabras oxítonas terminadas en vocal, y da pie a la escritura del presente artículo reflexivo, que tiene por objetivo mostrar la incidencia del relato mencionado en el aprendizaje del tildado en una estudiante de quinto grado en la sede rural Carboneras, de la institución Educativa Juana Caporal del municipio de Coper (Boyacá). Por medio del respaldo de referentes teóricos y la aplicación de actividades a partir de la anécdota, la cual fue aportada por la estudiante mencionada, se muestra la relación de la anécdota con la enseñanza de la ortografía de las palabras oxítonas, implementando actividades que pueden apreciarse con precisión en el asidero metodológico del presente artículo. Se relata la anécdota en un tiempo verbal (pretérito perfecto simple), que permite una comprensión práctica de la temática aquí abordada. Como resultado del aprendizaje del uso de la acentuación de dichas palabras, se ha evidenciado una escritura de textos con mayor sentido y coherencia.

Palabras clave: anécdotas, palabras oxítonas, enseñanza de la ortografía, pretérito perfecto simple.
*Institución Educativa

Juana Caporal - Boyacá

- Colombia

samuel@hotmail.com

***Institución Educativa

Juana Caporal - Boyacá

- Colombia

martinezluis01@yahoo.es

***: Universidad Pedagógica y

Tecnológica de Colombia

- Boyacá - Colombia

bsforense@hotmail.com

(c)(3) $\odot$ 


\section{Abstract}

Through the experience of the authors, it is possible to infer that the anecdotes of the grandfather, specifically the one titled: "Diánchiro de Carboneras", provides some strategies in the orthographic teaching of the oxytone words finished in a vowel, and gives rise to writing of the present reflexive article, which aims to show the incidence of the story mentioned in the learning of the ticked in a fifth grade student in Carboneras rural branch, of the educational institution Juana Caporal in Coper (Boyacá, Colombia). Through the support of theoretical referents and the application of activities from the anecdote, which was contributed by the aforementioned student, the relationship of the anecdote with the teaching of the orthography of oxytone words is shown, implementing activities that can be appreciated with precision in the methodological handle of the present article. The anecdote is told in a verb tense (simple past tense), which allows a practical understanding of the subject matter addressed here. As a result of learning to use the accentuation of these words, text writing with greater sense and coherence has been evidenced.

Key words: anecdotes, oxytone words, teaching of spelling, simple past tense. 


\section{Introducción}

El artículo "La ortografía desde los relatos anecdóticos del abuelo", es de tipo reflexivo y surge del proyecto de investigación: "La tradición oral: fuente de conocimiento y aprendizaje escritor", que se está desarrollando y forma parte del trabajo de grado para la Maestría en Educación en La Universidad Pedagógica y Tecnológica de Colombia. El proyecto proviene de una serie de diagnósticos que lograron determinar la carencia de una conciencia prosódica en los escritos de los estudiantes. La falta de dicha conciencia produce dificultad para la redacción de textos, tildando las palabras oxítonas o agudas, además de la falta de sentido que podría originarse; además de lo anterior, García (2010) dice que la falta de uso apropiado de la ortografía propicia una baja comprensión de lectura por cuanto la ortografía no se entiende debido a la cantidad de macro-reglas que tiene la lengua, por tal razón, se aplicó una estrategia basada en la anécdota, con el fin de lograr la comprensión y afianzamiento de este tema lingüístico, importante para el mejoramiento de la producción académica, comunicación, expresión y resultados evidentes en las pruebas internas y externas propuestas por el MEN.

Teóricamente y a través de la implementación de actividades pedagógicas, mediante el uso de las anécdotas del abuelo, específicamente la intitulada: "el Diánchiro de Carboneras"; es posible derivar algunas estrategias para la enseñanza ortográfica, principalmente, en el tildado de palabras oxítonas terminadas en vocal, estudio aplicado a los estudiantes de quinto grado, específicamente, con la estudiante Paula Alejandra Ortega Ortiz, de la sede rural Carboneras, de la Institución Educativa Juana Caporal, del municipio de Coper (Boyacá).

Un trabajo importante relacionado con el tema anterior, lo presenta Arrechea (2010) donde pretende la enseñanzaaprendizaje de la ortografía, en especial el tildado de palabras agudas y llanas, implementando diferentes talleres en pro del mejoramiento de este aspecto en niños de primaria teniendo en cuenta el contexto de ellos. También, ofrece una revisión teórica de algunos autores como: Alvero (1999), Balmaseda (2001), entre otros; quienes investigan y abordan la problemática ortográfica desde diferentes disciplinas.

\section{Asidero pedagógico sobre la escritura}

El MEN (1998), en los Lineamientos Curriculares de Lengua Castellana, menciona que:

La escritura no es, una actividad sólo intrínseca, pues es también extrínseca en tanto se moviliza entre voces de adentro y voces que provienen de afuera, que finalmente se realimentan, como ocurre en la lectura. Este movimiento se acentúa mucho más en la evaluación y corrección, actividad en la que se añade, se quita o se intercambia, en el movimiento paradigmático de la escritura. (p. 7).

Ahora bien, en relación con la oralidad, Vásquez (2010) dice que esta
El artículo "La ortografía desde los relatos anecdóticos del abuelo", es de tipo reflexivo y surge del proyecto de investigación: "La tradición oral: fuente de conocimiento y aprendizaje escritor" 
Tradicionalmente, la ortografía se ha enseñado mediante el aprendizaje mecánico y memorístico de una serie de normas que los alumnos han repetido hasta la saciedad, sin entender realmente el significado de lo que estaban diciendo. es quizá la primera mediación con que contamos cuando empezamos nuestras incipientes demandas por medio de la palabra que se complejiza hasta configurarse en relatos, fórmulas y canto. Esa oralidad, aprendida desde el vientre de nuestra madre, tan repleta de repeticiones y giros coloquiales, tan propios del ambiente en que nacemos $\mathrm{y}$ tan pegados a nuestros orígenes, esa oralidad, es el primer puente que tendemos hacia los otros. Digamos que es otro lazo de sangre a partir del cual establecemos un vínculo con los más cercanos, llámense familiares o miembros de la tribu. Por ella y con ella aprendemos una lengua, un credo, unos valores... Dicha oralidad se asemeja al seno de nuestra cultura.

Desde luego, para poder acceder a esos tesoros de la oralidad, se requiere desarrollar, al mismo tiempo, una facultad de escritura, pues se requiere de una serie de estrategias que permitan, no solo tener en cuenta la caligrafía, sino se debe tener un conocimiento de la realidad que se vive, porque se escribe sobre la experiencia, como en el caso de este documento, en donde la estrategia principal empleada fue las anécdotas de los abuelos, como método para la enseñanza y el mejoramiento de la ortografía adecuada en el proceso escritural de las palabras oxítonas (las que reciben el acento en la última sílaba) terminadas en vocal. "El término anécdota, atestado por vez primera en 1654 en Guez de Balzac, está unido, por su sentido etimológico, a la Historia, por un lado, y a la expresión de lo inédito por otro -Anécdota de Procopio- .” (Jiménez, 2007, p. 9).
Para ayudar a nuestros alumnos con la ortografía $y$, en especial, con la acentuación, se les debe hacer entender la importancia de escribir con ortografía "correcta", aludiendo a razones como que esta contribuye al fortalecimiento de la unidad de un idioma; pero, sobre todo, a que esta permite comprender con exactitud lo que se lee y facilita la exposición de lo que nosotros queremos expresar. A partir de ahí, es necesario trabajarla en clase como parte de la rutina diaria, no solo del profesor de Lengua Castellana y Literatura, sino de todos los profesores de las distintas asignaturas, haciendo ver así a nuestros alumnos que es erróneo pensar que las faltas de ortografía no encierran ninguna gravedad porque todo el mundo las comete, pero que se debe aprender a emplearla adecuadamente.

Tradicionalmente, la ortografía se ha enseñado mediante el aprendizaje mecánico y memorístico de una serie de normas que los alumnos han repetido hasta la saciedad, sin entender realmente el significado de lo que estaban diciendo. Es cierto que es necesario el conocimiento y estudio de estas normas, pero principalmente las que hay que enseñarles son las que tienen carácter general y no poseen cientos de excepciones, porque si no lo que se produce es el efecto contrario: crean confusión y perjudican la propia ortografía y, por ende, la escritura. Pero como resulta a veces tedioso para los alumnos, se puede proponer el estudio de estas normas por descubrimiento a través de juegos con tarjetas, por ejemplo: rimas, anécdotas, elementos de la tradición oral de cada lugar en el que se esté, entre otros. 
Otro método muy usual ha sido la técnica del dictado. A pesar de que este es uno de los instrumentos más útiles a la hora de practicar la ortografía, pierde su valor cuando este es utilizado solo para controlar el número de palabras erróneamente escritas, ya que la misión del mismo debe ser que, tras la realización de este, el alumno sepa algo más de léxico, morfosintaxis e incluso de literatura y estilo; y, sobre todo, puede resultar totalmente inútil cuando en él aparecen solo palabras técnicas o muy poco usuales, en lugar de palabras que usamos habitualmente $\mathrm{y}$ que son las que, precisamente por ello, debemos empezar por saber escribir correctamente.

También se les puede entregar a los alumnos textos que contengan faltas de ortografía para que ellos las corrijan. A los alumnos les encanta muchas veces encarnar este tipo de roles y casi siempre este está asociado a la faceta del "corrector". Ahora pues, serán ellos los que corrijan textos ortográficamente incorrectos y seguro que acertarán a la hora de descubrir los errores cuando vean que esa palabra queda mal escrita, porque las palabras son imágenes visuales y muchas veces no saben por qué, pero sí saben que así no está bien escrita, pues tienen en su mente la fijación de otra imagen de dicha palabra.

Continuado con este proceso, cabe decir que en algunas regiones del país las anécdotas desempeñan un papel muy importante, debido a que rescatan la cultura, unen a las familias, forman parte de las creencias y son instrumentos que pueden emplearse en la escuela; como la "anécdota del Abuelo", explicada supra, la cual fue escrita por uno de los estudiantes de grado quinto de la Institución. Ramírez (2009) menciona que "No tenemos que ir muy lejos, tampoco tenemos que invertir mayores recursos materiales y financieros, tan sólo necesitamos el recurso humano que está disponible en nuestras aulas y alrededor de ellas: los estudiantes, sus familias y la comunidad" (p. 3).

Desde la experiencia de los autores, se observala necesidad deun mayor esfuerzo en la práctica de la ortografía, lo cual es posible a través de la implementación de estrategias y materiales como la escritura de anécdotas o relatos históricos particulares de los abuelos, entre otros, con los cuales se realizan composiciones de textos, logrando que los educandos optimicen la ortografía; "Cualquiera que sea el enfoque adoptado para la enseñanza de la escritura, este deberá lograr que todos los niños y jóvenes lleguen a dominar el sistema gráfico y ortográfico de su lengua" (Vaca, 2014, p. 278). Para ello, se ha planteado una serie de actividades pedagógicas, donde se recopila información por parte de los educandos, propiciando el desarrollo de ambientes de aprendizaje que le permiten al estudiante proponer, crear, investigar, comparar y, sobre todo, realizar escritos que permitan perfeccionar la ortografía de las palabras oxítonas terminadas en vocal, como se explica en el asidero metodológico.

Dentro de las palabras oxítonas terminadas en vocal, es posible mostrar algunos ejemplos, como: Panamá, caí, tropezó, acaricié, comeré,
A los alumnos les encanta muchas veces encarnar este tipo de roles y casi siempre este está asociado a la faceta del "corrector". 


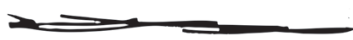

La ortografía es una muestra del desempeño en el área de Español. "Hay factores en común que afectan conjuntamente a la Comprensión lectora y a la Ortografía, y otros que afectan conjuntamente a la Reflexión sobre la lengua y a la Ortografia" (Backhoff et al. citados en Vernon \& Alvarado, 2013, p. 155). empujó, interrumpió, arrastró, llevaré, borojó. "El conocimiento ortográfico permite el procesamiento automático de las palabras, procesamiento que constituye la base para la comprensión y la producción de textos de calidad" (Perfetti \& Stanovich, citados en Diuk et al., 2016, p. 55). Una de las principales intenciones del desarrollo de este trabajo es el progreso de los estudiantes en cuanto a la ortografía de las palabras oxítonas terminadas en vocal, que como se argumenta en la cita anterior, es de gran importancia para la comprensión y escritura correcta de textos con el sentido adecuado, es decir, se procura que los estudiantes adquieran una conciencia prosódica o acentual.

La ortografía es una muestra del desempeño en el área de Español. "Hay factores en común que afectan conjuntamente a la Comprensión lectora y a la Ortografia, y otros que afectan conjuntamente a la Reflexión sobre la lengua y a la Ortografia" (Backhoff et al. citados en Vernon \& Alvarado, 2013, p. 155). Es decir, el conocimiento ortográfico tiene una influencia positiva sobre la comprensión lectora; y, obviamente, sobre la capacidad de expresarse por escrito. La enseñanza-aprendizaje de la acentuación de las palabras oxítonas y de otros aspectos ortográficos, es compleja; en tal medida, debe darse a lo largo de la educación básica, media y superior. Es así como, a partir de la clasificación de palabras, según su acentuación, ayuda a la mejor comprensión y a la producción de diferentes tipos de textos.

Teniendo en cuenta que en Español se usa una marca diacrítica llamada tilde para darle gráficamente el acento a una palabra, siempre sobre una vocal tónica; la tilde se hace importante, porque en principio, su ausencia o presencia permite determinar el significado de las palabras que contrastan por la posición del acento. Aun en palabras sin contraste con otras (como portón, pájaro, árbol), se denota la importancia del conocimiento en ortografía para lograr darle el sentido correcto a un texto. Ejemplo de esto, es la palabra "público" que hace referencia a que es conocido por mucha gente, y la palabra "publicó" que se refiere a darle a conocer a mucha gente algo, como puede ser una noticia o un artículo. Palabras homónimas pero que su significado lo determina la acentuación.

\section{La escritura de la anécdota "El Diánchiro De Carboneras"}

Cuenta la historia del abuelo que en la quebrada de Carboneras, del municipio de Coper (Boyacá), se ven apariciones de un ser extraño que ataca a los borrachos, como lo narra don Joselo (El Abuelo):

Un día que trabajé en la finca "Las Rositas", esmaltando potreros, como todos los días, con la diferencia que la suerte no me acompañó. La cuchilla de la máquina se rompió dos veces y eso es muy extraño, porque el terreno estaba limpio de piedras. Además, las cuchillas eran nuevas. No suficiente con eso, me encontré tres serpientes de las más venenosas del sector: la "talla x". Me tocó matarlas a machetazos, y siguió mi mala racha. El almuerzo, que llevé en hojas de bijao, se me apichó y el 
guarapo se me agrió. Renegué mi mala suerte muchas veces. Con la cuchilla rota dos veces, siendo las tres de la tarde no trabajé más.

Salí de los potreros al camino y se soltó un fuerte aguacero. Corrí a la casa más cercana y escampé. Me tomé unos torrosos y unos guarapos con mi amigo Darío, hasta que quedé bien pepo, en esas me cogió la noche. Me despedí y arranqué para la casa, que estaba como a unas dos horas.

Llegué a la quebrada y empecé a escuchar ruidos raros, tenebrosos, como pasos que me seguían, se juntó la oscuridad y la neblina; además, la linterna prestada se quedó sin pila. De un momento a otro sentí un escalofrío por todo el cuerpo, los ruidos eran cada vez más fuertes. Crucé la quebrada cuando algo me empujó al agua, me arrastró, me rompió la ropa, me golpeó y me rasguñó la espalda; no podía ver nada, solo sentí una fuerza que no me dejó parar. Me arrastró como cien metros, quedé inconsciente y desperté al otro día. Ese Diánchiro me laceró hasta los ojos, y además me dejó sin ropa. Pero no fui el único, ya otros paisanos cuentan que les ha ocurrido lo mismo, entonces, mucho cuidado con el Diánchiro de Carboneras.

Como se puede inferir, el tiempo verbal en el cual está escrita la anécdota es pretérito perfecto simple, junto con la mayoría de las palabras oxítonas que hacen parte de la anécdota son verbos regulares. Esto permite la práctica de la ortografía de estas palabras terminadas en vocal. Así mismo, es una narración atractiva para la estudiante, debido a que la representa y se identifica con los lugares y acontecimientos que en esta se narran.

El abuelo utiliza algunos términos del argot popular, como apichó (relacionada con la bebida artesanal fermentada), renegué(maldecir, denigrar, calumniar).

En la cultura boyacense, cabe resaltar la importancia que los campesinos y, en especial, los más antiguos le dan a las apariciones, encantos y manifestaciones sobrenaturales o que no tienen una razón científica o fácil de explicar, como lo expresa Ocampo (1977):

Los campesinos boyacenses respetan profundamente los lagos, las montañas y las rocas; ninguno habla de nadar en dichos lagos, y ni siquiera de lavar allí sus ropas. Consideran que los "espíritus" o los "encantos" están vinculados a los fenómenos físicos, los ríos, las montañas y las lagunas; inclusive cuando pasan cerca de ésta, hacen la señal de la cruz. Algunos campesinos boyacenses creen que los espíritus del agua no solo viajan bajo la tierra, sino también toman fuerza humana y caminan de un lugar a otro (p. 100).

\section{Asidero metodológico}

El presente documento es producto de una investigación de tipo estudio de caso, por cuanto se comprende la naturaleza de una práctica educativa, encaminada al mejoramiento de la ortografía. Yin (1993) define el estudio de caso como una herramienta valiosa de investigación, y su mayor fortaleza
El abuelo utiliza algunos términos del argot popular, como apichó (relacionada con la bebida artesanal fermentada), renegué (maldecir, denigrar, calumniar). 
En el desarrollo del proyecto de investigación "La tradición oral fuente de conocimiento y aprendizaje escritor", del cual subyace este artículo, cada estudiante lleva un cuaderno llamado "Narraciones de mi pueblo". radica en que a través del mismo se mide y registra la conducta de las personas involucradas en el fenómeno estudiado. El objetivo fundamental de la investigación consiste en mejorar la práctica a partir de una cultura más reflexiva sobre la relación entre procesos y productos en circunstancias concretas, como es la escritura.

El enfoque empleado es de tipo cualitativo. De acuerdo con Castaño y Quecedo (2003), puede definirse la metodología cualitativa como la investigación que produce datos descriptivos: las propias palabras de las personas, habladas o escritas, y la conducta observable. Los instrumentos empleados fueron talleres, observación participante, entrevistas, grupos de discusión, historias de vida, entre otras. Se recolectaron narraciones autóctonas, vivenciales $\mathrm{y}$ ancestrales que fueron aunadas con temáticas ortográficas.

Uno de los textos muestra de investigación de la estudiante Paula Alejandra Ortega Ortiz, estudiante del grado quinto, de la sede escuela rural de la Institución citada, evidenció que de las 36 palabras oxítonas terminadas en vocal en el escrito de la anécdota "El Diánchiro de Carboneras", no se tildaron, ante lo que el docente decidió explicar la acentuación de estas palabras. Cabe resaltar que no son las únicas palabras acentuadas en la narración de don Joselo, pues se encontraban otras, como por ejemplo: seguían, palabra paroxítona; además, palabra oxítona, pero terminada en consonante.

Como realimentación de la explicación, se le pidió a la estudiante que identificara las palabras terminadas en vocal, que en este caso específico son verbos en pretérito perfecto simple. A continuación, la estudiante pronuncia de manera contextualiza y ubica la tilde según las orientaciones explicadas por el maestro. Se le pide a Paula que contextualice la narración, leyéndola como si fuera propia, que se colocara en el papel del Abuelo Joselo, buscando con ello darle el sentido y entonación correcta a dicha narración.

En el desarrollo del proyecto de investigación "La tradición oral fuente de conocimiento y aprendizaje escritor", del cual subyace este artículo, cada estudiante lleva un cuaderno llamado "Narraciones de mi pueblo". En este, se plasman cada uno de los "testimonios" (Vansina, 1967, p. 33) recolectados de las entrevistas efectuadas a las personas más longevas de la comunidad, entre ellos los abuelos, en este cuaderno la estudiante plasma la anécdota con las correcciones correspondientes.

\section{Resultados}

Atravésdelarecopilación, realimentación y socialización, de la anécdota "El Diánchiro de Carboneras”, se logró la apropiación de la actividad del tildado de las palabras oxítonas terminadas en vocal, y más específicamente, las que son verbos regulares en participio perfecto simple, mediante actividades desarrolladas como: la explicación del funcionamiento de la acentuación, dictado, autocorrección de la anécdota, entre otras. La estudiante demostró, además, en sus recopilaciones y escritos posteriores, un mayor interés por analizar y acentuar un texto, dándole un sentido coherente. Además, comprendió 
la importancia de la correcta acentuación de las palabras, porque con ello se da una interpretación y contextualización propiciando comprender textos.

Por otra parte, se notó dificultad y confusión en la estudiante cuando tildó verbos irregulares en pretérito perfecto simple, como por ejemplo: estuvé- estuve. Este es otro tema que se trabaja a medida que Paula sigue recopilando más saberes populares.

Se siguen cometiendo errores, omisiones, tildado en palabras que no la tienen. Es un proceso lento, el tildado no se aprende de la noche a la mañana. Es un proceso que poco a poco va dando resultados, esto en gran medida por el interés, motivación y gusto de la estudiante por la escritura y la lectura.

\section{Conclusiones}

La anécdota del abuelo "el Diánchiro de Carboneras", al ser un relato interesante y misterioso, despierta el interés de la estudiante y puede ser empleada como herramienta de aprendizaje de las palabras oxítonas terminadas en vocal.

La mayoría de las prácticas docentes, a propósito de las fallas ortográficas, consisten en la repetición de una o varias veces de la palabra equivocada con el fin de afianzarla. En la enseñanza de la ortografía, hay un alto número de docentes que señalan el error y nada más, pero sería recomendable que fueran los estudiantes quienes los descubrieran y los marcaran con el fin de reconocer las propias fallas y mejorar en futuros escritos.
El aprendizaje de la ortografía de las palabras oxítonas terminadas en vocal, permite la adecuada comprensión y producción de un texto, debido a que el acento en las palabras le da el sentido que le corresponde, para lo cual es importante distinguir la sílaba tónica de las palabras.

La apropiación de la ortografía de las palabras oxítonas terminadas en vocal, se adquiere a lo largo de la formación académica, para esto deben buscarse estrategias que hagan este aprendizaje más efectivo y que acerquen al estudiante a su contexto académico.

A través de la experiencia de los autores, es viable y aconsejable que otros colegas puedan hacer uso de las anécdotas o narraciones del pueblo, como herramienta que facilite la aprehensión de temas relacionados con ortografía, además, porque mejora la comprensión y producción de textos. Por otra parte, contribuye también a la preservación de la cultura propia, evitando el desarraigo de la misma.

Crear una conciencia ortográfica en los estudiantes no es tarea fácil, debido al léxico tan variado y abundante que tiene nuestra lengua. Además, es un proceso de paciencia que amerita mucho tiempo de estudio, lectura, concentración y deseo del estudiante por aprender. Nuestra tarea como maestros, es motivar al estudiante con nuevas prácticas de aula, mostrándoles que la ortografía es de suma importancia para la comunicación y desempeño académico.
La anécdota del abuelo "el Diánchiro de Carboneras”, al ser un relato interesante y misterioso, despierta el interés de la estudiante y puede ser empleada como herramienta de aprendizaje de las palabras oxítonas terminadas en vocal. 


\section{Referencias}

Alvero, F. (1999). Lo esencial de la ortografía. La Habana, Cuba: Pueblo y Educación.

ArrecheA, D. (2010). Mejoramiento de la acentuación de palabras agudas y llanas en los alumnos de cuarto grado. (Tesis en opción al grado académico de master en ciencias de la educación). Universidad de Ciencias Pedagógicas Capitán "Silverio Blanco Núñez", Trinidad, Cuba.

Balmaseda, O. (2001). Enseñar y aprender ortografía. La Habana, Cuba: Pueblo y Educación.

CASTAÑo, C., \& QueCEDO, R. (2003). Introducción a la metodología de investigación cualitativa. Revista de Psicodidáctica, 14, 5-40.

Diuk B., Ferroni M., \& Mena M. (2016). Niveles de respuestas a una intervención en ortografía. Ciencias Psicológicas, 10(1), 55-61. Recuperado de http://www. scielo.edu.uy/scielo.php?script =sci_arttext\&pid=S1688-42212016000100006

Jiménez, D. (2007). La anécdota, un género breve: Chamfort. Cedille. Revista de Estudios Franceses, (3), 9-17. Recuperado de http://www.redalyc.org:9081/ articulo.oa\%20? $\mathrm{id}=80800303$

Ministerio de Educación Nacional. (1998). Lineamientos curriculares de lengua castellana. Recuperado el 15 de mayo de 2017, de http://www.mineducacion. gov.co/1759/articles-339975_recurso_6.pdf

Ocampo, J. (1977). Elpueblo Boyacense y su folclor. Tunja, Colombia: Ed. Cooperativa Ltda.

Perfetti, Ch., \& Stanovich, K. (1982). M.E. Reading. En R.E. Dillon \& R.J. Sternberg (Eds.), Cognition and instruction. New York: Academic Press.

Ramírez, M, R. (2009). Tradición oral en el aula. San José, Costa rica: La Coordinación Educativa y Cultural Centroamericana (CECC/SICA).

VACA, J. (2014). Serie Galileo para el Aprendizaje de la Ortografía. Revista de Investigación Educativa, (19), 278-318. Recuperado de http://www.redalyc.org/ articulo.oa? $\mathrm{id}=283131303010$

VAnsina, J. (1967). La tradición oral. Barcelona, España: Labor.

VÁsQuez, F. (2010). Ponencia: La oralidad, la lectura y la escritura. En: Proyectos institucionales de lectura: PILEO. Bogotá: Biblioteca Virgilio Barco.

Vernon, S. A., \& Alvarado, M. (2013). El desarrollo de acentuación gráfica en niños y jóvenes mexicanos. Revista Mexicana de Investigación Educativa, 56(18), 141-157. Recuperado de http://www.redalyc.org/articulo.oa?id=14025581007

YIn, R. (1993). Applications of Case Study Research, Applied Social Research Methods Series (Vol. 34). Newbury Park, CA, Sage. 